NBER WORKING PAPER SERIES

ARE MEDICAL PRICES DECLINING?

\author{
David M. Cutler \\ Mark McClellan \\ Joseph P. Newhouse \\ Dahlia Remler
}

Working Paper 5750
NATIONAL BUREAU OF ECONOMIC RESEARCH
1050 Massachusetts Avenue
Cambridge, MA 02138
September 1996

We are grateful to Ernie Berndt, Dennis Fixler, Richard Frank, Irwin Gerduk, Dan Ginsburg, Steve Goss, Zvi Griliches, Jon Gruber, Anne Martin, Bill Nordhaus, and Jack Triplett for helpful conversations, and to the Agency for Health Care Policy and Research, the Bureau of Economic Analysis, the Bureau of Labor Statistics, the Alfred P. Sloan Foundation, the Robert Wood Johnson Foundation, and the National Institute on Aging for research support. We, of course, are responsible for errors and interpretations. This paper is part of NBER's research programs in Aging, Productivity and Public Economics. Any opinions expressed are those of the authors and not those of the National Bureau of Economic Research.

(C) 1996 by David M. Cutler, Mark McClellan, Joseph P. Newhouse and Dahlia Remler. All rights reserved. Short sections of text, not to exceed two paragraphs, may be quoted without explicit permission provided that full credit, including $\mathbb{C}$ notice, is given to the source. 


\title{
ARE MEDICAL PRICES DECLINING?
}

\begin{abstract}
We address long-standing problems in measuring health care prices by estimating two medical care price indices. The first, a Service Price Index, prices specific medical services, as does the current CPI. The second, a Cost of Living Index, measures the net valuation of treating a health problem. We apply these indices to heart attack treatment between 1983 and 1994. Because of technological change and increasing price discounts, the current CPI overstates a chain-weighted price index by three percentage points annually. For plausible values of an additional life-year, the real Cost of Living Index fell about 1 percent annually.
\end{abstract}

David M. Cutler

Department of Economics

Harvard University

Cambridge, MA 02138

and NBER

dcutler@nber.harvard.edu

Joseph P. Newhouse

Division of Health Policy Research \& Education

Harvard Medical School

25 Shattuck Street

Boston, MA 02115
Mark McClellan

Department of Economics

Stanford University

Stanford, CA 94305-6072

and NBER

markmc@nber.harvard.edu

Dahlia Remler

Department of Economics

Tulane University

New Orleans, LA 70118 
The Consumer Price Index for medical care has increased more rapidly than the price of other goods and services for the past several decades. This "excess medical care price inflation" was particularly acute in the 1980 s, when the annual increase in the medical care CPI was 3.6 percentage points greater than the GDP deflator, compared with an excess of 1.2 and 1.5 percentage points in the two prior decades. The increased spread over the GDP deflator occurred despite a marked increase in price competition in medical care (e.g., Zwanziger and Melnick, 1988), which would be expected to reduce markups. Yet policymakers effectively treated the above-average measured medical care price inflation as true. They proposed at various times freezing all medical care prices, freezing particular prices such as drugs, and reducing prices paid by government programs, suggesting that they saw increased unit prices as an important cause of the sustained rise in medical care spending.

But measuring true changes in medical care prices is very difficult. ${ }^{1}$ In part, the difficulty stems from the fact that the bundle of medical services provided changes rapidly. In any market where consumption patterns change quickly, issues of sampling frequency and weighting become very important.

A second difficulty is that there are multiple bases of price in the market. While some purchasers pay the charge for each service (a day in the hospital, a pint of blood, etc.), others pay at a more aggregated level (for example, a hospital admission involving bypass surgery). And still others pay a fixed amount per person per year (capitation) without explicit reference to what

'Difficulties with the medical care CPI have been noted by Armknecht and Ginsburg (1992), Ford and Sturm (1988), Getzen (1992), Newhouse (1989, 1992), and Phelps (1992). 
services are provided. A price index should ideally be able to incorporate each of these pricing systems.

Perhaps the most important issue, however, is quality change. The value of medical care changes substantial over time, even if its physical characteristics remain the same. A day in the hospital or an hour in the operating room in 1990, for example, included much more highly concentrated nursing, monitoring, and other services than a day in the hospital in 1980. Even a pint of blood, a seemingly well-defined product, now includes more screening tests for infectious agents and safer packaging than it used to.

Quality adjustment is particularly important because consumers ultimately value the expected health consequences of their encounter with the medical sector, not the number of units of medical services they receive. ${ }^{2}$ A price index reflecting the cost of living ought to value this output (Griliches, 1992). In most situations, our presumption is that quality improvements reduce real price increases relative to nominal price increases. But quality improvements are valuable only if their expected benefits exceed their social costs. Because of moral hazard from health insurance and other market imperfections, this condition may not apply in medical care markets. Thus, the medical care CPI could be seriously biased, but even the direction of the bias is not entirely clear.

In this paper, we address these problems in the development of appropriate price indices

\footnotetext{
${ }^{2}$ This structure is analogous to previous work on the development of unbiased price indices for computers (where the inputs are the speed and memory of the computer and the output is the ability to perform specific tasks) or automobiles (where the inputs are characteristics of the car and the output is transportation and safety).
} 
for medical care. There are two conceptual price indices for this industry. The first is a Service Price Index - an index of the price of particular medical treatments over time. The Service Price Index corresponds most closely to current price indices such as the CPI. The Service Price Index does not have a natural quality adjustment, however. To incorporate quality change, we form a second index - a Cost of Living Index - that measures how much consumers would be willing to pay or would have to be compensated to accept changes in medical treatments and prices over time.

Because measuring inputs and health outputs is crucial in forming price indices, and because the relevant medical inputs and health outputs vary by disease, we focus on medical care for a particular disease: acute myocardial infarction (AMI) or heart attack. We choose AMI for several reasons. Heart attacks are common, with nearly one percent of the elderly population suffering a new heart attack annually. Indeed, heart disease, which includes heart attacks and related complications caused by blockages in the blood vessels supplying the heart, accounts for nearly one-seventh of medical spending and is the leading cause of death in the United States. In addition, the costs of treating heart attacks have increased substantially in recent years, with Medicare expenditures per heart attack rising about four percent annually in real terms (Cutler and McClellan, 1996). Our goal is to separate cost changes into changes in prices and changes in real output. Finally, an episode of heart attack treatment has a natural beginning point -- the attack itself -- and a highly-valued outcome -- survival -- which is relatively easy to measure. Thus it is easier to analyze the value of heart attack care compared to care for many other 
diseases where other outcomes are more relevant. ${ }^{3}$

We use two sources of data. The first is detailed data on quantities of care and charges from a single major teaching hospital (which we term MTH) between 1983 and 1994. Detailed data are essential in measuring changes in prices for particular medical services. We also use data from Medicare on major AMI treatments and mortality for all elderly patients who had a heart attack between 1984 and 1991.

We reach two conclusions about medical care price indices. First, service price indices are particularly sensitive to which prices are included in the index and how frequently the basket of goods is reweighted. When we use list prices for a constant set of services over time, we find increases in the price index above general inflation of over three percentage points annually. When we use transactions prices for the variable set of services that patients actually consume over time, we find real price increases of less than one percent annually.

Second, the increase in the Cost of Living index is even smaller, and our best estimate is that the real Cost of Living index is actually falling, by about one percent annually. This estimate is naturally somewhat speculative, since it depends on the assumed value of life. But given the improving survival of AMI patients, even conservative estimates of that value suggest that the real Cost of Living Index has been constant or falling over our time period. If the heart attack example generalizes, it suggests that current price indices are substantially overstated, and

\footnotetext{
${ }^{3}$ Of course, other outcomes related to quality of life also matter for AMI patients, and we also consider the implications of changes in quality of life for our price indices. But almost 40 percent of elderly heart attack patients die within a year of AMI, compared with about five percent of all elderly, making survival a highly relevant consideration for valuing the care received.
} 
that the relative price of medical care may in fact be falling.

The paper is structured as follows. In the first section, we discuss the theoretical issues involved in calculating price indices for medical care. In the second section, we discuss treatments for heart attacks. The third section describes the data. The fourth and fifth sections present our price indices. The last section concludes.

\section{I. $\quad$ Price Indices for Medical Care}

In forming a price index for medical care or anything else, one must first specify the good being priced. For most goods, particularly non-durables, this is not much of a problem. The consumption good is simply the physical output of the industry; if the nature of the good does not change, then the price of the output over time can be used to construct an unbiased price index. Medical care poses several difficult issues, however. The first problem is in measuring what the industry provides. The goods produced by medical providers are a complex array of personal interactions and diagnostic tests, leading to insights about the nature of a patient's health problem, followed by a range of treatments including drugs, procedures, devices, and counseling that may or may not affect the course of a particular individual's illness. Many of these components of medical care are difficult to measure precisely, and they often differ from case to case. For example, physician time spent chatting with a mildly-ill patient is different from time spent diagnosing problems with a more severely-ill patient. A price index must find some way to differentiate among these different goods.

The measurement of services is complicated by the fact that multiple bases of price exist 
in the market. In traditional fee-for-service billing, prices exist for over 7,000 particular physician services (such as brief hospital visit, interpretation of an x-ray, etc.). Many health insurance plans today price a more aggregated bundle of services, e.g. an all-inclusive payment to a hospital for a bypass surgery operation for an AMI patient, or even a single capitated payment for all treatments for all medical problems in a period of time. Price indices should ideally capture both of these levels of aggregation.

The third difficulty is that consumers rarely pay the entire cost of medical care out of pocket. Most of the payment is typically made by an insurer, public or private. Ultimately, however, consumers must bear the cost of medical care, through lower wages, higher prices, or increased taxes. We thus allocate all of the costs of medical care to consumers in forming price indices. ${ }^{4}$

The final difficulty is that to a first approximation consumers value the expected effect of medical care services on their health and not the medical care services themselves. This is true for the consumption value of any product - consumers do not value an orange per se, but value the visual, taste, and nutritional consequences of its consumption. Medical care is a particularly difficult case, however, because the expected health output is difficult to measure and changes over time. For example, when a new clinical trial is published showing that a particular cardiac drug has a larger effect on improving mortality for heart attack patients than had previously been supposed, doctors and patients revise their expectations about the value of the drug; assuming no

\footnotetext{
${ }^{4}$ Nordhaus (1996) discusses the need for considering indirect costs for a variety of nonmarket goods.
} 
change in nominal prices as a result of the trial, such a trial should result in a decrease in the real cost of medical care. Designing methods to incorporate this type of situation are difficult, however, particularly since the prevalence of insurance and price discounts means that list prices are not a good reflection of marginal valuation.

To formalize these ideas in the context of various price indices, we begin by introducing some theory and notation. Suppose that consumers may have a series of diseases, indexed by $d$ (one disease can consist of not being sick). Having disease $d$ results in the receipt of medical care $m_{d}(t)$, a vector of constant-quality treatments. If a new procedure is developed or the ability to perform a given procedure gets better over time, this would be represented as an addition to the set of $m_{d}$. For the moment, we want to ignore the issue of how $m_{d}$ is determined; it may be through markets, through an administrative mechanism, through the beliefs of doctors, or a combination of all of these factors. We return to this below. The expected welfare of a representative consumer $i$ in any period $t$ is:

$$
U_{i}(t)=\sum_{d=1}^{D} \pi_{d}(t) \cdot U_{i}\left(H_{i}\left(d, m_{d}(t)\right), Y_{i}-p_{i}(t) \cdot m_{d}(t)-T_{i}(t)\right)
$$

where $\pi_{d(t)}$ is the probability that the person has disease $d$ at time $t, U$ is the consumer's expected utility, $H$ is the health of the person, which depends on the disease and the expected effects of medical care received, $Y_{i}$ is income (assumed to be constant over time), $p_{i}(t)$ is the vector of effective price to person $i$ of medical care at time $t$, and $T_{i}(t)$ is lump-sum payments (insurance premiums or taxes) for medical services. $p \cdot m+T$ is spending on medical care, so that 
the second argument of the utility function is just the consumption of non-health goods.

In specifying this utility function we assume that medical services do not have independent consumption value, beyond their effect on health. Otherwise we would need to include them in the utility function separately and keep track of them throughout the indices. Excluding the direct consumption value makes the calculation of consumer price indices much simpler and seems to be a reasonable approximation. ${ }^{5}$

This specification may not capture some interactions between current medical services and future utility. For example, elderly people whose life is prolonged but who are left partially disabled may suffer increased risk of future uninsured nursing home expense. The utility cost of this risk should be counted as a cost of current medical care consumption, just as the longer life is a benefit of current medical care consumption. For simplicity, we do not consider such interaction effects in this paper. But we do discount future health benefits and costs to current dollars.

The consumer's welfare may change over time for several reasons. First, the distribution of medical service use and payments may differ by age. If medical payments increase more rapidly than receipt of medical services as a person ages, welfare will fall over time. Conversely, when medical care is subsidized at older ages, welfare increases over the lifetime. We abstract from this in our analysis; by allocating all treatment-related expenditures to each consumer, we

${ }^{5}$ This assumption will not hold exactly for some medical services that have consumption value for non-health reasons (e.g., hospitals have some hotel-like qualities). Moreover, some economists (e.g., Newhouse, 1977, Fuchs, 1993) have emphasized the "caring" role of medical care -- the process of care itself - has inherent value to the sick and to other members of society in itself, even if it has no consequences for the patient's health outcomes. 
implicitly analyze consumers with a constant age and income over time.

Second, disease incidence may change. Entirely new diseases such as AIDS may be added to the set of possible illnesses, and other diseases such as smallpox may be eliminated. More generally, changes in lifestyles and medical care may change the incidence of a given set of diseases. Better diet, reduced smoking, and increased exercise have lowered the incidence of heart disease over time, and thus resulted in increased welfare.

We also abstract from these effects by estimating price indices for a single disease. It is conceptually straightforward to apply similar methods to other diseases, and to reconstruct an aggregate price index from the specific illnesses. With a single disease, welfare is given by:

$$
U(t)=U(H(m(t)), Y-p(t) \cdot m(t)-T(t)) .
$$

With these assumptions, welfare changes are only a function of changes in medical treatments, their expected effects, and payment over time. The question we pose is: how do these practice and payment changes affect the price of the medical services industry's product? We distinguish two price indices, one based on medical care services and the other based on the effects of medical services on expected utility.

Service Price Index. The first index, which we term a Service Price Index (SPI), is the price of a representative bundle of medical goods and services over time. We use the term Service Price Index to reflect the focus on medical care services rather than patient welfare. To form the Service Price Index, we consider a typical set of treatments in period $t_{0}, m\left(t_{0}\right)$. The Laspeyres 
Service Price Index is the relative cost of this fixed set of treatments over time:

$$
S P I_{t_{0}, l}=\frac{p\left(t_{1}\right) \cdot m\left(t_{0}\right)}{p\left(t_{0}\right) \cdot m\left(t_{0}\right)}=\alpha \cdot \frac{p\left(t_{1}\right)}{p\left(t_{0}\right)}
$$

where $\alpha$ is the vector of the share of each service in total costs in the base period. There are many potential Service Price Indices, depending on the bundle of services chosen as the market basket and how frequently the basket of goods is resampled. We discuss both of these issues in Section IV.

Because it prices specific medical care services, the Service Price Index may be biased from the standpoint of describing true changes in the cost of living related to medical care. Even with very detailed measurement of medical quantities, it is possible that the nature of the measured service changes over time, or that other unmeasured services provided with the measured service change over time. For example, the price of a cardiac catheter may rise over time, but the features of the catheter (e.g., size, maneuverability, etc.) may change, so that a catheter in the base period and the current period does not represent the same medical product. In addition, the Service Price Index may not capture the health consequences of changes in medical services. In the catheter example, if the product improvements result in better expected health outcomes associated with use of the catheter, or if learning-by-doing associated with past catheterization use results in better health outcomes in the future, then the price index should fall. But a Service Price Index generally will not capture this price reduction. Consequently, we define an alternative price index that accounts explicitly for the value of the health care 
outcomes.

Cost of Living Index. Following the literature on true cost of living indices (Fisher and Shell, 1972), we define the Cost of Living Index (COL) as the amount consumers would be willing to pay (or would have to be compensated) to have today's medical care and today's prices, when the alternative is base period medical care and base period prices. The change in the cost of living between $t_{0}$ and $t_{1}$, denoted $C$, is the amount of compensation required to equalize utility in those two states. It is implicitly defined from: ${ }^{6}$

$$
U\left(H\left(m\left(t_{1}\right)\right), Y-p\left(t_{1}\right) \cdot m\left(t_{1}\right)-T\left(t_{1}\right)-C\right)=U\left(H\left(m\left(t_{0}\right)\right), Y-p\left(t_{0}\right) \cdot m\left(t_{0}\right)-T\left(t_{0}\right)\right)
$$

Taking a Taylor series expansion around $t_{0}$, using $x$ to represent consumption, and rearranging terms, we obtain:

$$
C=\frac{U_{H} H_{m}}{U_{x}} d m-d(p \cdot m+T)
$$

The first term on the right hand side of equation (4) is the health benefit of changes in medical care, expressed in dollars. The second term is the change in the cost of medical care. If $C$ is

${ }^{6}$ Fisher and Shell (1972) define the cost of living index in terms of expenditure functions. The income required to reach utility $\mathrm{U}$ over time is: $\mathrm{COL}=\mathrm{e}\left(\mathrm{U}, \mathrm{p}_{1}\right) / \mathrm{e}\left(\mathrm{U}, \mathrm{p}_{0}\right)$. For our purposes, it is easiest to work with the utility function directly. The two are equivalent, however, since $\mathrm{COL}=1-\left(\mathrm{e}\left(\mathrm{U}, \mathrm{p}_{0}\right)-\mathrm{e}\left(\mathrm{U}, \mathrm{p}_{1}\right)\right) / \mathrm{e}\left(\mathrm{U}, \mathrm{p}_{0}\right)=1-\mathrm{C} / \mathrm{Y}_{0}$. 
positive, the consumer is better off in period $t_{l}$ than he was in period $t_{0}$ and conversely. There is no necessary presumption, however, that changes in medical treatments - even with prices constant - will increase welfare.

The Laspeyres Cost of Living Index between period $t_{0}$ and period $t_{l}$ is just the index of changes in $C$ scaled by initial income: ${ }^{7}$

$$
C O L_{t_{0}, l}=1-\frac{C}{Y_{0}}
$$

It is important to note that the cost portion of the cost of living index is the change in the total cost of care, not the change in a Service Price Index (i.e. $p \cdot m+T$, not $p$ ). If consumers care only about health output, the price of a representative bundle of services is irrelevant; only the total cost of treatment and its expected consequences for health matter.

The key question in implementing a Cost of Living Index is what to assume about the relation between the value and cost in the Cost of Living formulation. In most markets, a reasonable assumption is that the marginal consumer's marginal valuation of the good equals its cost. Thus, we can link costs and value by observing how much consumers are willing to pay for the particular components in a bundled product. This is the foundation of hedonic analysis (Griliches, 1971). In medical care markets, however, this is not a tenable assumption. When medical care decisions are made by patients who are insured at the margin or by health care

7 The Cost of Living Index can be formed using chain weights or other methods of intertemporal aggregation. 
providers whose interests may not coincide with those of the patient, there is no presumption that the marginal value of care equals its social cost. Thus, we cannot a priori use hedonic analysis to measure changes in the cost of living.

A second approach is to specify a model for how consumption decisions are made. Then, using the observed path of consumption and spending, one could infer the change in the cost of living. This is the approach taken in Fisher and Griliches (1995) and Griliches and Cockburn (1994) for the case of generic drugs. Many complex medical treatment decisions may be involved even in the treatment of a single health problem, however, and there is no generallyaccepted model for how such decisions are made. We thus do not pursue this approach.

A third approach is to use direct evidence on the expected value of medical care in improving health. Then the Cost of Living Index can be calculated using the measured cost and value differences directly. We implement this approach in Section V, based on aggregate changes in health outcomes and in medical expenditures for AMI patients.

\section{The Treatment of Acute Myocardial Infarction}

Before discussing a price index for AMI, we sketch some of the major treatment decisions involved. A person who suffers a heart attack will almost always be admitted to a hospital, unless he or she dies before reaching one, because the initial treatments for AMI are all administered in an inpatient setting. We thus begin our episode of care with the initial hospital admission of the AMI patient. While they survive, patients may receive care for their heart attack, in and out of hospitals, over the following months. For example, patients may receive 
tests or invasive diagnostic procedures in the initial hospital admission, and be readmitted for additional tests or invasive procedures later on. We group all of these admissions into a single temporally-based episode of medical care, rather than an arbitrary grouping such as a hospital admission. For our Service Price Index, we define an episode as including all treatments that occur within 90 days of the AMI; this time period has been used extensively in previous studies of acute AMI care (e.g., Udvarhelyi et al., 1992, McClellan, McNeil, and Newhouse, 1994).

There are several major treatment options for patients with heart attacks. One method involves medical management of the heart attack. In the acute period medical management includes drug therapies, monitoring technologies, and other nonsurgical intensive interventions for complications such as heart failure or irregular heart rhythms. Later, it may include drug therapy and counseling to promote a healthy lifestyle and reduce the risk of future heart attacks. This type of care involves many important technologies -- for example, thrombolytic (clotbusting) drugs were developed in the 1970s and used on a wide-scale basis in the 1980s -- but does not include invasive procedures to improve blood flow to the heart. ${ }^{8}$

Invasive cardiac treatments begin with cardiac catheterization - a diagnostic radiologic study of blood flow to the heart muscle. Catheterization was developed in the late 1960s and became more widely used in the treatment of patients with heart disease over the next decade. If a catheterization detects "significant" blockage, a range of revascularization procedures may be applied. Two major types of revascularization procedures have become widely used: bypass

\footnotetext{
${ }^{8}$ Administering an intravenous drug is invasive, strictly speaking, but much less so than the major cardiac procedures that follow.
} 
surgery, a major open-heart operation that involves bypassing blocked blood vessels by splicing a vein or artery around the blockage, and angioplasty, a percutaneous (less invasive) procedure that seeks to restore blood flow via inflating a balloon amid the blockage. Bypass surgery was also developed in the late 1960s. Angioplasty is more recent. It was first applied clinically in the late 1970s but was not used on a widescale basis until the mid-1980s.

The fact that the content and intensity of heart attack treatment can vary widely, and that many of these treatments and their consequences are difficult to measure, illustrates the price index problems described above. We elaborate on these issues at length in our construction of price indices.

\section{Data and Price Measurement}

Data. We use two sources of data to form our price indices. The first is a complete set of detailed services, charges, demographic information, and discharge abstracts for all heart attack patients (patients discharged with a principal diagnosis of ICD-9 CM codes 410) admitted to a major teaching hospital (MTH) between 1983 and 1994. Every specific billable service that the hospital provided is reported in the data. This enables us to observe the quantities of medical care inputs at the most disaggregated level that is technically possible, and so permits the formation of a Service Price Index with minimal measurement bias. We restrict the sample to those patients for whom the observed heart attack was their first at this hospital, roughly 300 episodes annually. ${ }^{9}$ Table $\mathrm{A} 1$ shows the sample size by year.

\footnotetext{
${ }^{9}$ We do not know if the patient had an earlier heart attack elsewhere. However, we do
} 
The second source of data is Medicare claims records for all elderly patients with a heart attack between 1984 and 1991. We again form an episode by linking a patient's care over time. The Medicare claims records contain much less detail on services received than our hospitalspecific service data; only major procedures and days in the hospital are reliably coded. However, the Medicare data have two important advantages relative to the MTH data. First, because Medicare is the primary payer for the vast majority of elderly Americans, we are able to construct comprehensive estimates of expenditures on medical care for almost all elderly AMI patients from 1984 to 1991 . As Appendix Table A1 shows, this is roughly 230,000 patients annually. We limit our analysis to hospital costs, since hospital costs comprise the predominant expense in caring for AMI patients. Second, one can link Medicare data to Social Security death records and thereby determine survival outcomes.

Measuring Prices. At MTH we do not have transactions prices but rather charges or list prices. Until recently, the official indices for medical care, including hospital care, were based on such list prices. But many payers do not pay list price. For example, for Medicare and Medicaid patients, who account for about 40 percent of hospitals' revenues, hospitals receive an administered price (e.g., after 1984 Medicare payment was based on the Prospective Payment System). Likewise, many Blue Cross plans receive discounts off charges. Preferred Provider Organizations [PPOs], increasingly common in recent years, usually pay a discount off of list prices. As a result, list prices have become increasingly unrelated to typical transactions prices.

know if they were transferred to MTH from another hospital. We have experimented with restricting the sample to non-transfers, without important effect on the results. 
Dranove, Shanley, and White (1991) show that in California between 1983 and 1988 the use of list prices rather than transactions prices resulted in a 40 percent overstatement of the hospital price increase. Ideally, price indices would be based on transactions prices, which better approximate actual resource use and the opportunity cost of the resources involved.

We use charges to compare MTH with the hospital component of the CPI; this method corresponds to the construction of a CPI-like index for heart attack treatment at MTH during the period of our study. For purposes of estimating an index that is closer to transactions price, however, we deflate charges to reflect the hospital's accounting cost. The resulting cost-based prices increase by one percentage point less than charges per year. ${ }^{10}$ We use actual transactions prices for Medicare in our indices. ${ }^{11}$

Because of the attention paid by policymakers to the difference between the medical care CPI and economy wide inflation, we deflate all of our indices by the GDP deflator. All dollar figures are in 1991 dollars.

${ }^{10}$ Calculating accounting costs is reasonably standardized across hospitals because until 1988, Medicare paid at least partly on the basis of accounting costs. In our case we deflate charges using the cost-to-charge ratio for the hospital as a whole.

"Many believe that Medicare patients were increasingly subsidized by non-Medicare patients over the time period, as limitations on Medicare payments were made in periodic deficit reduction efforts (Prospective Payment Assessment Commission, 1996). Alternatively, Medicare may have paid closer to marginal cost and fixed costs were increasingly shifted to private payers (for a relevant model see Glazer and McGuire, 1994). Ideally, we would include all patients with their transactions prices. If cross-subsidies to Medicare patients were rising over time, results based on Medicare-only transactions prices would be biased down. 


\section{Service Price Indices}

In this section, we discuss the formation of Service Price Indices. From Section I, the Service Price Index is defined as the relative cost of a given set of treatments over time. There are many potential Service Price Indices, varying along two dimensions: the basket of goods that is priced (detailed services or a more aggregated set of treatments), and the frequency with which the basket of goods is resampled (annual or less frequently). We discuss the empirical implications of both of these choices.

\section{A. Pricing Basic Components}

The most commonly used medical care price index in the United States is the medical care component of the Consumer Price Index (CPI). We thus start with this index. The CPI prices the basic components of medical services. To calculate the hospital component of the CPI, the BLS prices charges for six hospital services at each hospital outlet: two room services (for example, charges per day for semi-private rooms and medical intensive care unit [ICU] rooms), three other inpatient services (for example, operating room time or electrocardiograms [ECG]) and one outpatient service (for example, outpatient ECG). ${ }^{12}$ These services are aggregated across hospitals to form hospital room, other inpatient hospital services, and outpatient hospital services sub-indices. These sub-indices are then combined to form the hospital and related services subindex, which in turn enters the overall medical CPI. The goods priced, and the hospitals in the sample, are kept constant for 5 years, at which time both hospitals and goods are resampled.

\footnotetext{
${ }^{12}$ Note that Medicare and Medicaid transaction prices are excluded from the CPI.
} 
Appendix 1 describes the sampling and aggregation in more detail.

Figure 1 shows the real (relative to the GDP deflator) medical care CPI from 1983 to 1994, and Table 1 shows average rates of growth. Over this time period, the real medical CPI rose by 3.4 percent annually. The real hospital component of the CPI increased even more rapidly, 6.2 percent annually.

To examine how representative our hospital and disease are for forming price indices, we formed a synthetic CPI for the treatment of heart attacks at MTH. We attempted to match the current CPI as well as possible, as described in Appendix 1. Because the medical care CPI is based on list prices, we computed a synthetic CPI based on hospital charges. As Figure 1 and Table 1 show, the real CPI for heart attacks at MTH grew at an annual rate of 3.3 percent, almost the same as the overall medical care CPI but well below the 6.2 percent hospital component of the CPI. To reflect more accurately what the typical payer is paying for medical care, we formed a second synthetic CPI, based on the estimated accounting costs of treating heart attacks. This index, also shown in Figure 1 and Table 1, grew about a percentage point less, at an annual real rate of 2.4 percent.

Our synthetic CPIs are much noisier than the national series (Figure 1). This is not surprising since they are formed for only one hospital and one disease, and price increases at a particular hospital do not occur smoothly over time. For example, the synthetic CPI increase in 1985 is largely caused by a repricing of cardiac catheterization in that year, and the increase in 1989 is largely the result of an increase in the price of intensive care unit rooms. In each case, the increase in the CPI is followed by a relative decline as there are smaller price changes for 
several years afterwards. Averaged over the whole time period, the cumulative increases are still substantial.

The medical care CPI does not change the quantity of goods that are priced over time. For example, the hospital room component always prices the cost of one day in a hospital, independent of how long patients actually stay in the hospital. Occasionally, new hospitals are added and others are deleted, but the set of goods priced remains the same. Because of this, the CPI may not reflect the price change for the set of goods that is typically purchased. An alternative approach to a basic components index is to choose the average patient and price the basket of medical services provided to that patient over time (Scitovsky, 1967). We term this a Patient Weighted Price Index (PWPI). The PWPI is similar to the new Producer Price Index (PPI) that the Bureau of Labor Statistics compiles and to some of the changes scheduled in the CPI. In the PPI, for example, a patient from a particular DRG is sampled, and that patient's bill is repriced every month for five years. For patients paid on a fee-for-service basis, the PPI is like our Patient Weighted Price Index with a 5-year chain weight. ${ }^{13}$

The principal limitation of the PWPI (and other basic components indices) is that it may not be able to capture the same treatment over time. Some goods disappear from use and others newly appear. This item-substitution needs to be accounted for. The detailed MTH data permit the extent of the problem of market basket change to be quantified. In our heart attack patients at

${ }^{13}$ The PPI is based on actual transactions prices, whether charges, discounted charges, or DRGs. For patients whose bills are paid for on a fee-for-service basis, the bill is in principle repriced each month. In fact, the total charges or discounted charges are usually increased by whatever amount the hospital's chargemaster increases. 
MTH, we can match spending for 98 percent of charges in consecutive years, but only 42 percent of charges in periods five years apart, and 27 percent of dollars in periods 11 years apart (the maximum time in our sample).

Some of these market-basket changes are nearly identical substitutions, largely new code names for products and services that are roughly therapeutic equivalents, such as the addition of equivalent analgesics or acid-suppressing drugs. Others may represent incremental improvements within a given family of services, such as a new variety of intensive-care unit rooms, but there is no easy way to quantify the value of these improvements in an output price index. When we allow for these straightforward substitutions, 78 percent of expenditures can be matched over the entire time period, 85 percent can be matched over five years, and 98 percent can be matched annually.

In addition, truly new goods appear. For example, intraortic balloon pumps -- small pumps inserted near the heart that can temporarily help the heart pump blood -- were nonexistent in 1987 but had grown to almost one percent of the average heart attack patient's bill by 1994 . We link these new goods as we are able to do so, but again make no adjustment for potential quality change associated with the new good. Our approach is consistent with the BLS linking method (Bureau of Labor Statistics 1992). ${ }^{14}$

${ }^{14}$ The BLS treats new and obsolete goods using three possible methods. In some cases, a new good is considered to be a direct and fully equivalent replacement for an old good (termed direct comparability). In other cases, quality adjustments are made for the shift from an old to a new good (termed direct quality adjustment), although this method is rarely used in practice due to the difficulties in quantifying quality improvements. Other new goods are linked into the old index, which is equivalent to assuming that the quality-adjusted price change in the substitution period is exactly equal to the price change of the other goods in the category. For our longer 
The upper line in Figure 2 and Table 1 shows the Laspeyres PWPI. This index is much like the synthetic CPI, increasing by 2.8 percent annually in real terms.

With rapid changes in the bundle of goods consumed, as in medical care, an index based on a constant treatment bundle may quickly become unrepresentative. Table 2 shows that, at least in some respects, treatments consumed by AMI patients have changed fundamentally during the period of our study. The first block of Table 2 shows the share of patients receiving different cardiac treatment regimens over time: medical management, cardiac catheterization only, bypass surgery, and angioplasty. The first set of columns is for the Medicare sample; the second set of columns is for patients at MTH.

In both sets of data, use of more intensive procedures has skyrocketed. In the mid-1980s only about ten percent of elderly heart attack patients received at least one of these intensive cardiac procedures (35 percent at MTH, including non-elderly). By the early- to mid-1990s, 40 percent of patients with a heart attack were treated with the cardiac procedures ( 75 percent at MTH). Use of all the procedures grew rapidly, with angioplasty growing particularly rapidly in MTH.

indices, linking underweights the kinds of goods that appear and disappear frequently, such as pharmaceuticals, and overweights the kinds of goods that exist over long periods, such as ICU rooms.

The BLS is trying to integrate quality changes into the new Producer Price Index. In principle, hospitals are supposed to report when treatment for the patient has materially changed, so that quality adjustments can be made. In practice, however, few hospitals do so. This may be because treatment changes are less obvious when they occur gradually as opposed to all at once. In the case of AMI, for example, the large changes in treatment over a five- or ten-year period are the cumulative effect of many modest changes in treatment; it is not obvious that hospitals could easily identify these changes as material and report them in any given year. 
Moreover, within these treatment regimens, there are dramatic changes in medical inputs. For example, among the medically managed patients at MTH, length of stay in the hospital fell by 57 percent and ICU days fell by a quarter (not shown). Length of stay for bypass surgery patients fell by 22 percent. The use of other resources for bypass patients increased, however. Operating room time, for example, rose by 38 percent.

As treatments consumed diverge from the mix in a fixed-weight index, the index yields increasingly biased estimates of the price increase facing a typical patient. To address this problem, more frequent resampling of the basket of goods is required. We consider two chainweighted PWPIs. One PWPI reweights the bundle of treatments every five years, and the other reweights it annually. Figure 2 and Table 1 show that the Laspeyres bias is substantial. Compared to annual real price growth of 2.8 percent for the Laspeyres index, the 5-year chainweighted index increases by 2.1 percent annually, and the annual chain-weighted index increases by only 0.7 percent annually. The difference in these indices results almost entirely from the weight placed on room charges. Between 1983 and 1994, the price of a hospital room rose by 60 percent, while the average length of stay for AMI patients fell by 36 percent. $^{15}$

\section{B. Pricing Treatments}

Increasingly, payments to health care providers are moving away from the basiccomponents level. For example, Medicare payment is made on the basis of the four treatment

${ }^{15}$ The growth of the chain-weighted index need not always exceed that of the Laspeyres index. If length of stay reaches a minimum, for example, the difference could be in the other direction. 
regimens shown in Table 2. Each treatment regimen is a separate DRG, and hospitals receive a fixed amount for every patient in that DRG. ${ }^{16}$ Price indices based on such major treatment regimens avoid the major limitations of pricing basic components, by implicitly reweighting changes in the basic components of the treatment regimen as they occur. We thus form a service price index that prices the major treatment regimens to compare to our basic components indices.

Forming the Treatment Price Index requires definition of major treatment options and the collection of comprehensive data on payments for the treatment regimens. We use the four treatment regimens defined in Table 2, to match current Medicare practice. We have data on prices and quantities of treatment regimens for both the national Medicare sample and the MTH data. We present results for both samples.

The lower panel of Table 2 shows the prices of our different treatment regimens over time. Reimbursement conditional on a treatment regimen was relatively constant or even falling over time. This is particularly true in the Medicare sample, where the range of real cost changes is from -6 percent annually (for angioplasty) to 2 percent annually. The reductions in reimbursement were typically by design. Angioplasty reimbursement was reduced in 1986 as Medicare administrators cut payments to reflect more accurately the estimated cost of performing the treatment; catheterization-only payments were reduced as more catheterizations were performed during the initial hospital stay rather than on a subsequent admission. Reimbursement

\footnotetext{
${ }^{16}$ This is a bit of a simplification. There are actually 3 DRGs for medically managed heart attacks, and 2 each for the other treatment regiments, depending on whether the patient had complicating conditions or died. There are also outlier payments for particularly costly or longstay patients. Still, the grouping into these four categories is the dominant source of payment variation. See McClellan (1995) for more details on DRG payment methods.
} 
for medically managed heart attacks or bypass surgery increased marginally (see Cutler and McClellan, 1996, for more details.)

The MTH accounting cost data generally show the same pattern, with two exceptions. First, the accounting cost of angioplasty increased in MTH, as opposed to the 6 percent decrease in the Medicare sample. This largely reflects the difference between costs and Medicare reimbursement. Second, the growth of bypass surgery costs in the MTH sample is greater than the payment growth in the Medicare sample, by about 1 percent per year. The reason for this difference is not entirely clear. It may be that the mix of cases in the hospital changed over time into a more severely ill group.

The fact that payment within each treatment regimen was relatively constant implies that price indices that adjust for changes in the frequency of use of each treatment regimen over time will not rise substantially. This is shown empirically in Figure 3 and Table 1, which present annual chain-weighted price indices at the treatment level. The pattern in the Medicare data is striking. There was essentially no increase in the Price Index through 1990, and then a mild increase in 1991. Over the entire time period, the total change in the Price Index was only 0.6 percent per year. The Price Index based on MTH data is again noisier than the index based on national Medicare data. Indeed, the MTH index is particularly variable because annual fluctuations in the average severity of admissions affect this index. Still, the average growth of the index is 0.4 percent annually. ${ }^{17}$

${ }^{17}$ We formed an alternative price index using a three year moving average of costs for each treatment regimen and the share of patients receiving each treatment regimen. The resulting index fell by 0.1 percent annually. 
Thus, for both the Medicare and MTH data, the growth of treatment-level price indices is about one-half percent annually. This is roughly the same as the growth of the annual chainweighted PWPI, but substantially below the 3.3 percent increase of the synthetic CPI. We thus conclude that adjusting for the difference between list and transactions prices and incorporating changes in the bundle of what is actually consumed can have a dramatic effect on medical care inflation. Our preferred Service Price Indices increase about 0.5 percent per year, roughly 3 percentage points less rapidly historically than official price indices.

\section{The Cost of Living Index}

The biggest difficulty with the Service Price Index is adjusting for quality. A Service Price Index only captures changes in quality that occur with changes in the measured quantities of goods and services that are included in the index, and even these changes may not be weighted properly. In this section, we form a true Cost of Living Index to value quality change explicitly.

\section{A. Methodology}

The value of medical care is given by the change in the length and quality of life. Since survival is a very important outcome for patients with a heart attack and is much easier to measure than is morbidity, we focus predominantly on changes in life expectancy. Consider a person with a heart attack in period $t$ who dies $s$ periods after their heart attack. The value of remaining life for that person is Value ${ }_{s}(t)=\sum_{j=0}^{s} \frac{V_{i}(t) \cdot a_{j}}{(I+r)^{j}}$, where $V_{j}(t)$ is the value of life $j$ years in the future, $a_{j}$ is 1 if the person lived the entire period and $1 / 2$ if the person died during the 
period, ${ }^{18}$ and $r$ is the real interest rate (assumed to be 3 percent).

Ignoring quality of life changes amounts to holding $V_{j}(t)$ constant over time. ${ }^{19}$ Then, the value of remaining life in year $\mathrm{t}$ is $\operatorname{Value}_{s}(t)=V \cdot l_{s}$, where $l_{s}=\sum_{j=0}^{x} \frac{a_{j}}{(I+r)^{j}}$. If a share $d_{S}(t)$ of people die in interval $s$ after their heart attack, the average value of remaining life for the entire heart attack population is:

$$
\operatorname{Value}(t)=\sum_{s=0}^{\infty} V \cdot d_{s}(t) \cdot l_{s}
$$

We divide the costs of this additional life into two parts: the baseline costs of maintaining life, which we assume are constant each year $\left(C^{O}\right)$, and the (discounted value of the) additional costs from the care provided in treating the heart attack, which may vary over time $(C A M I(t))$. Adding over people, total costs are given by:

${ }^{18}$ This assumes that all people who died during an interval died exactly halfway through that interval. Empirically, after the first year (which we model using finer time intervals), deaths among AMI patients are approximately evenly spread through the time period.

${ }^{19}$ The value of a year of life may also vary across people. Years of life for a healthy 70 year-old are likely to be worth more than years of life for a comatose 90 year-old, for example. Indeed, it need not be the case that the value of a lifeyear is greater than its social cost. We ignore this distinction in our analysis. 


$$
\operatorname{Cost}(t)=\sum_{s=0}^{\infty} C^{o} \cdot d_{s}(t) \cdot l_{s}+C^{A M t}(t)
$$

The net valuation of remaining life after a heart attack is just the difference between the value and cost of additional lifeyears. We divide this into two parts: the net value of a lifeyear given the baseline cost of that year $\left(P=V-C^{o}\right)$; and the cost of AMI treatment required to produce those lifeyears:

$$
\text { Net Value of Remaining Life }(t)=\sum_{s=0}^{\infty} P \cdot d_{s}(t) \cdot l_{s}-C^{A M I}(t)
$$

To proceed we must quantify the net value of a lifeyear $(P)$. There is great uncertainty about the worth of a life (Viscusi, 1993). Rather than specify one particular number, we use a range of estimates that roughly span the literature. Our benchmark estimate is $\$ 25,000$ per year. We use upper and lower bounds of $\$ 50,000$ per year and $\$ 10,000$ per year. ${ }^{20}$ Note that all of our estimates are positive, so that we have ruled out a situation where the individual is alive but society wishes they were not.

${ }^{20}$ One way to gauge these estimates is to sum them into the value of a life. For an individual who is 40 years old, remaining life expectancy is about 40 years. With a $\$ 25,000$ per year value of a lifeyear, the (undiscounted) value of his remaining life is $\$ 1$ million. Our range is $\$ 400,000$ to $\$ 2$ million. Survey evidence on the value of life for people around age 40 is $\$ 3$ million to $\$ 7$ million (Viscusi, 1993), so our central estimate is conservative. 


\section{B. Estimating the Cost of Living}

Implementing the cost of living empirically requires measuring the effects of changes in AMI treatment on life expectancy and on the costs of medical care. Figure 4 shows cumulative mortality rates for the elderly for various time periods after a heart attack: one day; 90 days; and 1 through 5 years. Substantial reductions in mortality rates following a heart attack have occurred in the elderly. Mortality during the initial hospital stay fell nearly two percentage points between 1984 and 1991. Mortality at one year fell by considerably more, five percentage points. Because the mortality data only extend through the end of 1992 , we cannot measure mortality rates in 1991 for time periods longer than a year. Still, the data through 1987 suggest declines in cumulative mortality rates at periods beyond one year as well.

It is important to recognize that these changes represent changes in average health following a heart attack. A substantial amount of evidence suggests that the marginal amount of medical care - even care for heart attacks -- provides benefits at relatively high cost (McClellan, McNeil, and Newhouse, 1994; Cutler, 1995; McClellan, 1995; Cutler and Staiger, 1996; McClellan, 1996; McClellan and Newhouse, 1996). In examining the Cost of Living for the average heart attack patient, we care about the change in average health. For other purposes, such as examining the efficiency of the medical sector, we care about marginal changes in health.

It is also important to recognize that other factors besides changes in the medical technologies used to treat heart attacks may lead to changes in average health following a heart attack. Three kinds of factors are important. The first is changes in the mix of heart attack patients. Demographics are one source of change, which we adjust for in our calculations. But 
there are other, subtler changes in the mix of patients that may be important. For example, better control of cardiac risk factors such as high blood pressure and high cholesterol levels may reduce or delay the occurrence of AMI. Thus, over time, actual AMI patients may have more or less severe blood vessel blockages, or they may be more or less likely to suffer from other comorbid diseases by the time the AMI occurs. The effects of these trends on the mortality risk of AMI patients is difficult to predict.

A second factor is environmental changes unrelated to medical care. For example, public health programs and even private advertising may make AMI patients more conscious of the benefits of reduced smoking and a careful exercise program, leading to lifestyle modifications that reduce the risk of subsequent heart attacks. Similarly, innovations in the food industry leading to new products with lower fat and salt content could also contribute to survival conditional on a heart attack. In this case, it would appear that correlated changes in heart attack treatments were very productive, even though the changes in treatment may not have caused the survival improvement.

The third factor is medical care for conditions other than AMI that are also experienced by AMI patients. For example, some AMI survivors may also suffer from diabetes. Improvements in treatment for diabetes would show up as improved survival among patients having a heart attack, even though the heart attack treatment may not have contributed to the longevity gains.

While we cannot completely address these issues, we do attempt corrections for some of them. We describe our approach briefly here and in more detail in Appendix 2. We start by 
forming demographically-adjusted mortality data for the AMI population. We divide the population into ten demographic groups, based on age $(65-69 ; 70-74 ; 75-79 ; 80-84 ;$ and $85+)$ and sex. For each group, we form average mortality for the time periods shown in Figure 4. Using the average demographics of heart attack patients over the 8 year period, we form an adjusted cumulative mortality series and the share of the initial population dying in each interval after the AMI. Since our mortality data extend only through 1992, some extrapolation of life expectancies is required for later years in the sample; our methods are described in Appendix 2. Furthermore, for people who lived at least five years after the heart attack, we do not have sufficient long-term mortality data to quantify their expected survival. For this group, we project life expectancy based on national lifetables but with a higher annual mortality rate that is characteristic of the heart attack population. ${ }^{21}$

The first column of Table 3 shows life expectancy for elderly patients who have had a heart attack in each year. In 1984, life expectancy following a heart attack was 5 years and 2 months. Life expectancy rose over time; by 1991, it was 5 years and 10 months, an increase of 8 months.

We need to compare the net valuation of these additional months to the net additional AMI and related condition treatment costs that produced the additional months. To measure these costs, we add up Medicare reimbursement for all inpatient services received in the year after the

${ }^{21}$ Since we have no information on changes in life expectancy beyond 5 years, we assume that it is constant at its 1984 level throughout the period. This is almost certainly a lower bound, since mortality rates for the population as a whole and for the AMI population in the first 5 years after the heart attack were both falling. 
AMI, adjusted over time for the changing demographic mix of the AMI population. By one year after the heart attack, most of the direct costs of the episode should have been incurred, and while there may be other indirect costs of the AMI episode beyond one year, it is difficult to separate these costs from any general time trends in the use of medical care by the elderly. The second column shows the increase in spending in the year after the heart attack. For the average elderly heart attack patient, expenditures increased by $\$ 3,600$ over the seven year period.

The next three columns show the net change in utility from the change in medical treatments -- the value of additional life less the costs required to produce it. For our benchmark estimate of $\$ 25,000$ net valuation of a lifeyear, the change in net benefits was about $\$ 11,000$ over the period. The range of this benefit is between $\$ 2,000$ and $\$ 26,000$ for the lower and upper values of a lifeyear. In each case, the value is positive -- on net consumers are better off in 1991, after the change in heart attack treatments and prices, than they were in 1984 , before the change in heart attack treatment.

To form a price index, we need to scale these net valuations by the cost of reaching baseline utility in the reference year. Total resource use among the elderly, including in-kind transfers as well as consumption, is roughly $\$ 25,000$ per capita per year. Since the average elderly person with a heart attack had a life expectancy of just over five years in 1984, the discounted value of the resources involved in this length of life is about $\$ 110,000$. We scale our estimate of the net gain from medical care by this baseline cost of life to form a Cost of Living Index. $^{22}$

${ }^{22}$ This is a Laspeyres Cost of Living Index. To form a chain-weighted index, we would 
Figure 5 shows the resulting Cost of Living Indices. For our middle estimate, the Cost of Living fell by about 9 percent over the period, or -1.1 percent per year. The range of estimates is roughly no change to about -3 percent per year. Naturally, the specific numbers here are subject to substantial variability. Our most important conclusion, though, is that even under conservative assumptions, the Cost of Living is constant or decreasing over time. Indeed, under our baseline assumptions the Cost of Living would be falling even if the increase in medical costs had been 300 percent greater than it was in actuality.

This set of calculations assumes that all of the increase in life expectancy after an AMI is a result of changes in medical practice for the AMI. As noted above, environmental factors or treatments for other conditions may also affect AMI mortality or costs. There is no way to definitively parcel out the factors leading to the increase in longevity. One sensitivity test for our estimates is to look at the difference in life expectancy and costs for the AMI population relative to the elderly population as a whole. Any trends in environmental factors that are common for all of the elderly would be differenced out by this approach.

While we implement this approach, it is important to note that this adjustment is not perfect. Changes in environmental factors or the quality of other medical treatments that disproportionately affect AMI and non-AMI patients will lead to differences in the two series that would not cancel out. For example, improvements in cancer treatments would affect the non-AMI population more than the AMI population and would incorrectly reduce our estimates

scale by the cost of remaining life for the previous year. Because the net valuation and cost of life are approximations, we do not experiment with alternative indices. 
of the health effects of AMI treatment. The bias could work the other way as well.

Despite these difficulties, comparing trends in life expectancy for the AMI and general populations is a valuable sensitivity test of our results. We estimate changes in longevity and hospital costs for the overall elderly population using lifetables from the Social Security Administration and hospital spending for elderly Medicare beneficiaries (see Appendix 2). In both cases, we weight the data to match the demographic composition of the AMI population.

The next two columns of Table 3 show changes in life expectancy and medical costs for the elderly population as a whole. Life expectancy for the elderly population was 10 years and 3 months in 1984. Life expectancy rose over the 8 year period, but by only half as much (4 months) as for the AMI population. ${ }^{23}$ And real Medicare expenditures rose as well, by about $\$ 400$.

The final column of the Table shows an adjusted measure of the change in the Cost of Living Index: the change in life expectancy for the AMI population beyond that for the general population, less the increase in costs for the AMI population beyond that for the general population. We present results for our intermediate assumption of a $\$ 25,000$ net valuation of life. The estimates suggest that the benefits of AMI treatment still outweigh the costs. Over the whole time period, the change is about half as large -- $\$ 5,000$ relative to $\$ 11,000$ in looking at just the AMI population -- but still positive. ${ }^{24}$

${ }^{23}$ Some of the increase in life expectancy for the population as a whole is a result of increased longevity for the AMI population. Only about 1 percent of the population has a new heart attack each year, however, so this concern is not particularly important.

${ }^{24}$ Using the low and high end estimates of the value of a lifeyear provides a range of net valuations of about $\$ 0$ to about $\$ 13,000$. 
Thus, while our Cost of Living measures are necessarily uncertain, they uniformly suggest that the Cost of Living following a heart attack has been either constant or falling over time. Our best guess is that the real Cost of Living Index declined by about 0.5 to 1 percent annually between 1984 and 1991.

These calculations do not account for changes in the quality of life for AMI patients. If the average quality of life increased, then the Cost of Living Index based on survival changes alone is too small; conversely, if reductions in the quality of life of survivors occurred, then the decline in the Cost of Living index is too large. Other research suggests that accounting for morbidity factors would not change our conclusions materially. A detailed analysis of the AMI data used here (McClellan, 1996) showed that, between 1984 and 1991, the share of AMI patients experiencing heart failure requiring hospital admission in the year after AMI increased by 1.4 percentage points (approximately 15 percent). As a worst case estimate, this is about onequarter of the reduction in mortality. On the other hand, the share of AMI patients experiencing long-term complications of ischemic heart disease requiring hospitalization declined slightly, suggesting quality of life improvements. And other research indicates that the rapid growth in cardiac procedure use in the US elderly population may have resulted in improvements in functional status that were larger than the mortality improvements (Rouleau et al., 1993). Because heart failure and further problems with ischemic heart disease represent the principal complications of AMI, and these changes are not clearly in a uniform direction, we suspect that accounting for changes in average quality of life would not substantially alter our Cost of Living index. 


\section{Conclusions}

In this paper we develop and estimate two types of price indices for medical care provision: one based on the price of specific medical care services, and another based on the net value of the changes in medical care to consumers. We estimate these indices using data on heart attack treatments for the Medicare population, and for all patients at a large teaching hospital.

Our preferred price indices increase substantially less than do current medical care price indices. Relative to the GDP deflator, all of our indices suggest that medical prices have at most risen modestly in recent years, and may well have fallen. The differential for Service Price Indices is particularly high, due to differences between list and transactions prices and changes in the bundle of goods consumed. One relatively easy change in index calculation involves switching from reliance on an index like the current CPI to one that reprices treatments for patients with a given health problem annually; for heart attack patients, such a change would reduce measured index growth by almost three percentage points annually.

However, even these indices are unlikely to capture the net value of changes in medical care very accurately. The rapidity of changes in consumption in the health care industry and the potential difficulties in interpreting the value of these many changes make a strong case for trying to value health explicitly and develop real Cost of Living indices. For patients with a heart attack, our best estimate is that the real Cost of Living actually fell over 1984-1991 period. There is clearly a great deal of uncertainty in this estimate, but even under conservative assumptions, we find no change in the Cost of Living.

Our research also sheds light on several other public policy issues. Often policies to limit 
spending on medical care have focused on limiting the prices paid for medical care. The economic justification for such policies is presumably the assumption that expenditure growth is due in large part to price increases from market failures, a conclusion consistent with the behavior of traditional price indices. In fact, if true prices are nearly constant or falling, then focusing on price reductions to control costs may be misguided. It is important to test this conclusion with other data and other diseases.

Second, it is important to extend these indices to a changing health care environment. The basic-components Service Price Index is designed for a fee-for-service era, where providers had charges for particular treatments and insurers paid these charges. As managed care increases in importance, however, this type of pricing will become increasingly less common. Insurers will pay providers on a DRG, or even a capitated basis. In such a situation, the price of specific services will not be well-defined, and even the price for treating a specific disease may lose its meaning. Calculating price indices in this more aggregated context will be essential to keep medical price indices relevant for policymaking. 


\section{References}

Armknecht, Paul A., and Daniel H. Ginsburg, "Improvements in Measuring Price Changes in Consumer Services: Past, Present, and Future," in Zvi Griliches, ed., Output Measurement in the Service Sector, Chicago: University of Chicago Press, 1992.

Bureau of Labor Statistics, "The Consumer Price Index," Chapter 19 in BLS Handbook of Methods, Bulletin 2414, September 1992.

Cutler, David M., "The Incidence of Adverse Medical Outcomes Under Prospective Payment," Econometrica, February 1995, 63(1), pp. 29-50.

Cutler, David M., and Mark McClellan, "The Determinants of Technological Change in Heart Attack Treatment", mimeo, August 1996.

Cutler, David M., and Doug Staiger, "Measuring the Value of Medical Progress," mimeo, December 1995.

Dranove, David, Mark Shanley, and William D. White, "Does the Consumer Price Index Overstate Hospital Price Inflation?” Medical Care, August 1991, 29(8), pp. 690-696.

Fisher, Franklin M., and Zvi Griliches, "Aggregate Price Indices, New Goods, and Generics," Quarterly Journal of Economics, February 1995, 110(1), pp.229-244.

Fisher, Franklin M., and Karl Shell, The Economic Theory of Price Indices, New York: Academic Press, 1972.

Ford, Ina Kay and Philip Sturm, "CPI Revision Provides More Accuracy in the Medical Care Services Component," Monthly Labor Review, April 1988.

Fuchs, Victor, The Future of Health Policy, Cambridge, MA: Harvard University Press, 1993.

Getzen, Thomas E., "Medical Care Price Indexes: Theory, Construction, and Empirical Analysis of the U.S. Series, 1927-1990," in Advances in Health Economics and Health Services Research, JAI Press, Inc., 1992, pp. 83-128.

Glazer, Jacob, and Thomas G. McGuire, "Payer Competition and Cost Shifting in Health Care," Journal of Economics and Management Strategy, Spring 1994, 3(1), pp. 71-92.

Griliches, Zvi, editor, Price Indexes and Quality Change, Cambridge, MA: Harvard University Press, 1971. 
Griliches, Zvi, editor, Output Measurement in the Service Sector, Chicago: University of Chicago press, 1992.

Griliches, Zvi, and Iain Cockburn, "Generics and New Goods in Pharmaceutical Price Indexes," American Economic Review, December 1994, 84(5), pp. 1213-1232.

McClellan, Mark, “Hospital Reimbursement Incentives in Medicare,” mimeo, 1995.

McClellan, Mark, "Changes in the Marginal Value of Medical Care,” mimeo, 1996.

McClellan, Mark, and Joseph P. Newhouse, "The Marginal Benefits of Medical Treatment Intensity," mimeo, Harvard University, 1995.

McClellan, Mark, and Joseph P. Newhouse, "The Marginal Costs and Benefits of Medical Technology: A Panel Instrumental Variables Approach," Journal of Econometrics, in press.

Newhouse, Joseph P., "Medical Care Expenditure: A Cross National Survey," Journal of Human Resources, Winter 1977, 12:1, pp. 115-125.

Newhouse, Joseph P., "Measuring Medical Prices and Understanding Their Effects -- The Baxter Prize Address," Journal of Health Administration Education, Winter 1989, 7(1), 19-26.

Newhouse, Joseph P., "Medical Care Costs: How Much Welfare Loss?," Journal of Economic Perspectives, Summer 1992, 6(3), pp. 3-21.

Nordhaus, William, D. "Beyond the CPI: An Augmented Cost of Living Index," Yale University mimeo, 1996.

Phelps, Charles, Health Economics, New York: Basic Books, 1992.

Prospective Payment Assessment Commission, Medicare and the American Health Care System: Report to the Congress, Washington: The Commission, June 1996.

Rouleau, Jean L., Lemuel A. Moyé, Marc A. Pfeffer, et al., "A Comparison of Management Patterns After Acute Myocardial Infarction in Canada and the United States," New England Journal of Medicine, 328(11): 779-84, March 18, 1993.

Scitovsky, Anne A., "Changes in the Costs of Treatment of Selected Illness, 1951-67," American Economic Review 57: 1182, 1967.

Shapiro, Matthew, and David Wilcox, "Causes and Consequences of Imperfections in the 
Consumer Price Index," mimeo, 1996.

Viscusi, W. Kip, "The Value of Risks to Life and Health", Journal of Economic Literature, 31 (4), 1912-1946.

Zwanziger, Jack, and Glenn A. Melnick, "The Effects of Hospital Competition on the Medicare PPS Program on Hospital Cost Behavior in California," Journal of Health Economics, December 1988, 7(4), pp.301-320. 


\section{Figure 1: Consumer Price Indices}

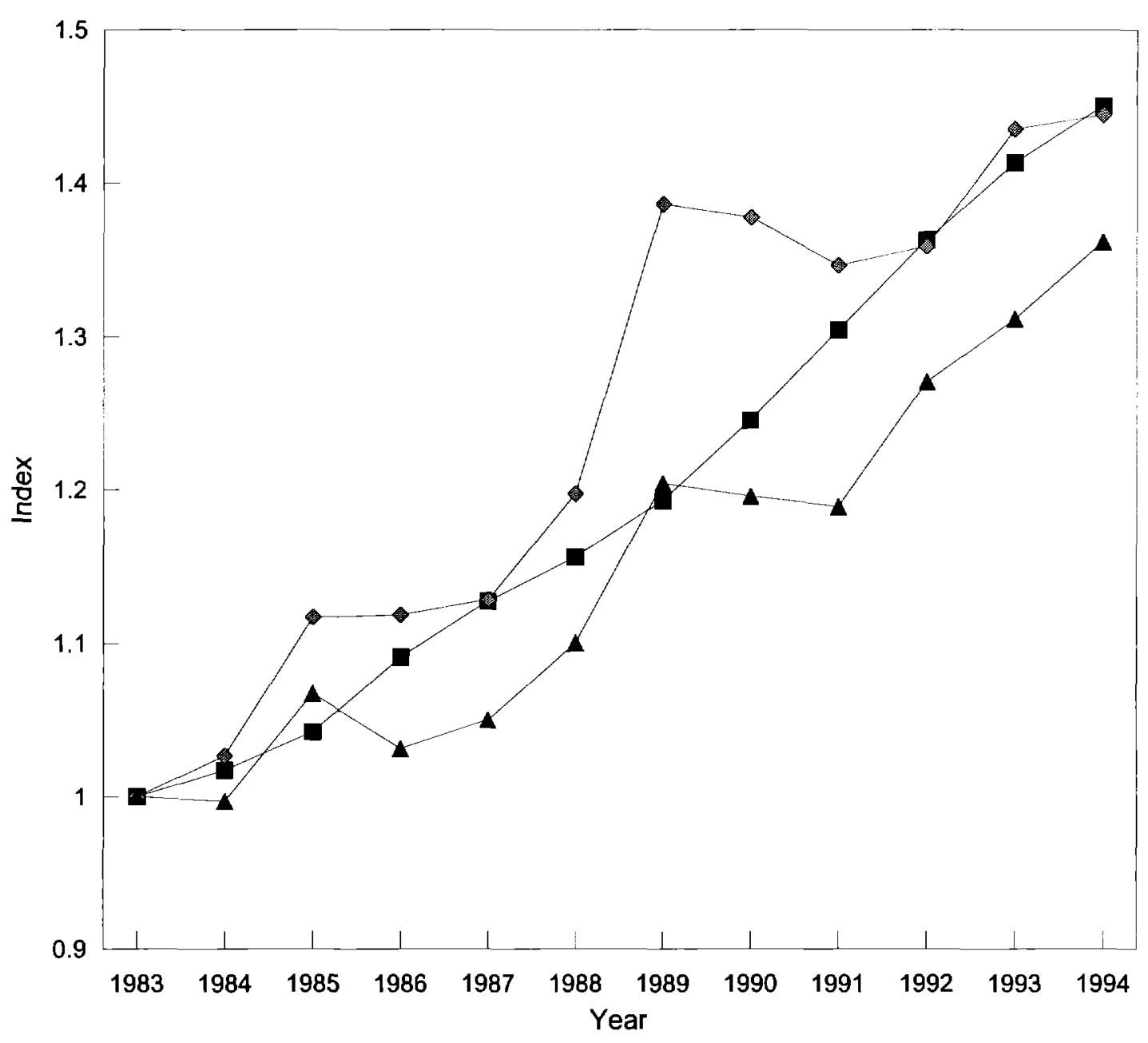

Medical Care CPI $\quad$ Synthetic CPI - Charges $₫$ Synthetic CPI - Costs 


\section{Figure 2: Patient Weighted Price Indices}

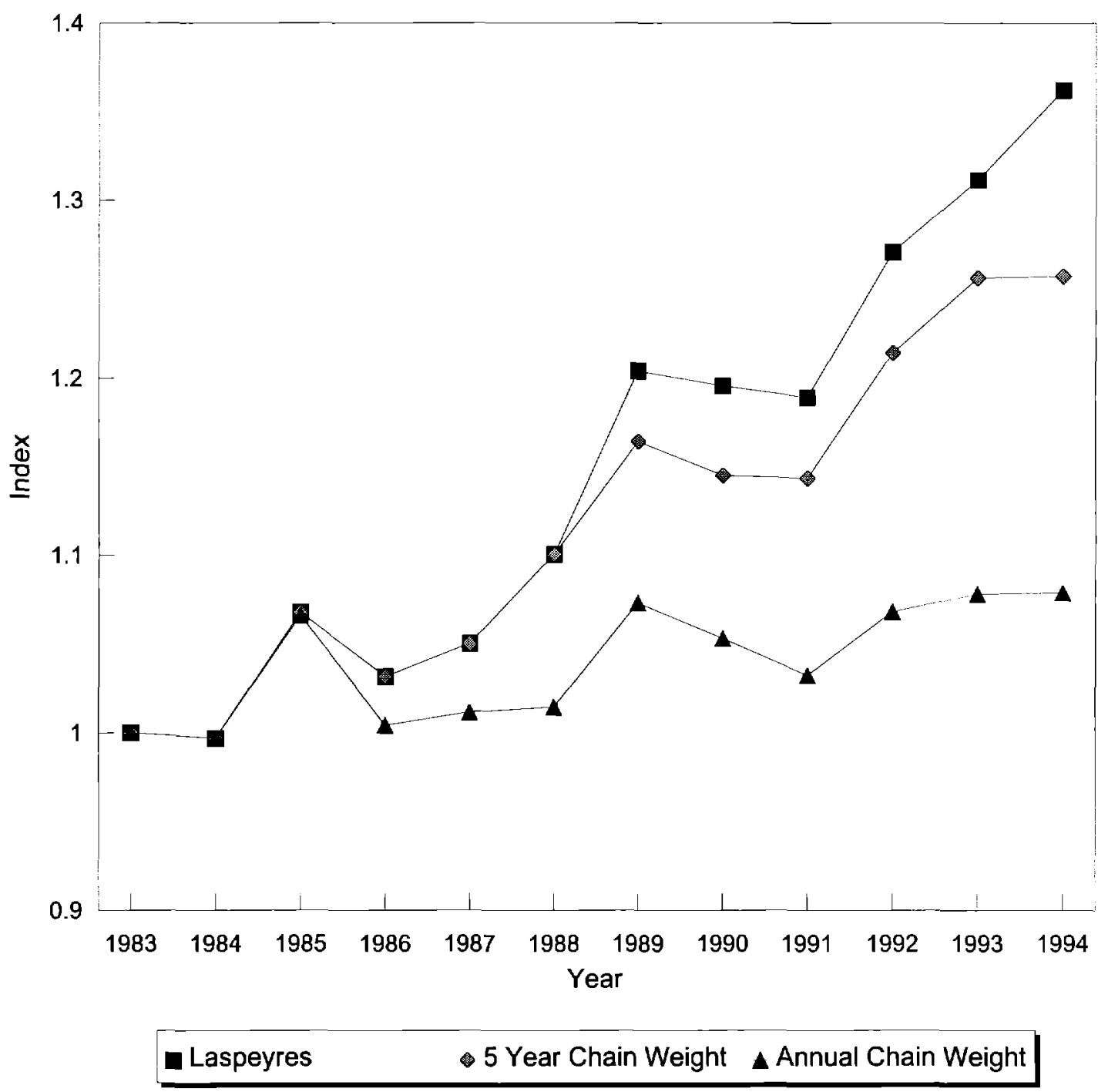

Note: Index is normalized to 1 in 1983. 
Figure 3: Treatment Price Indices

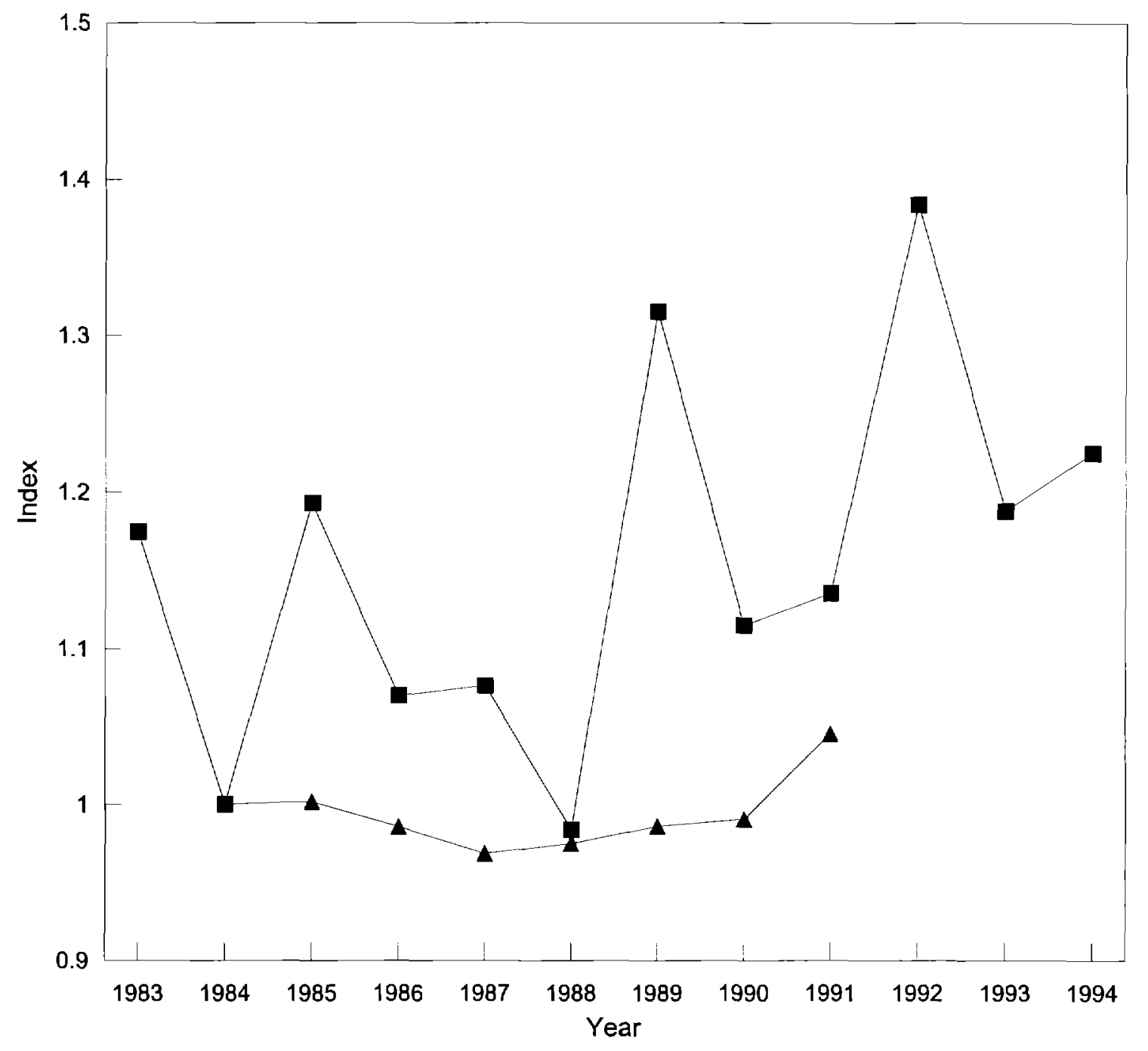

MTH $\triangle$ Medicare

Note: Index is normalized to 1 in 1984. 


\section{Figure 4: Changes in Mortality Rates After AMI}

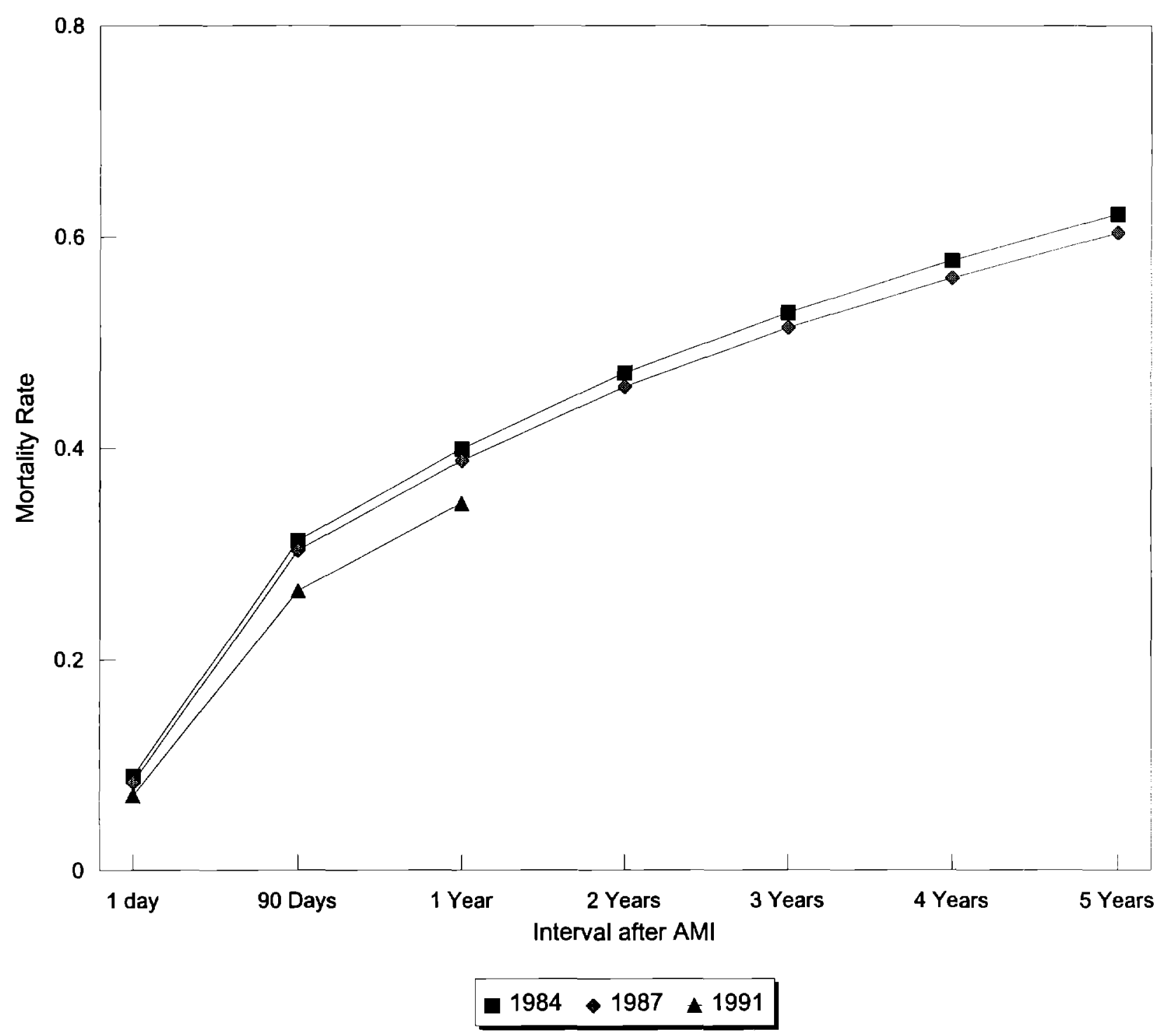




\section{Figure 5: Cost of Living Index}

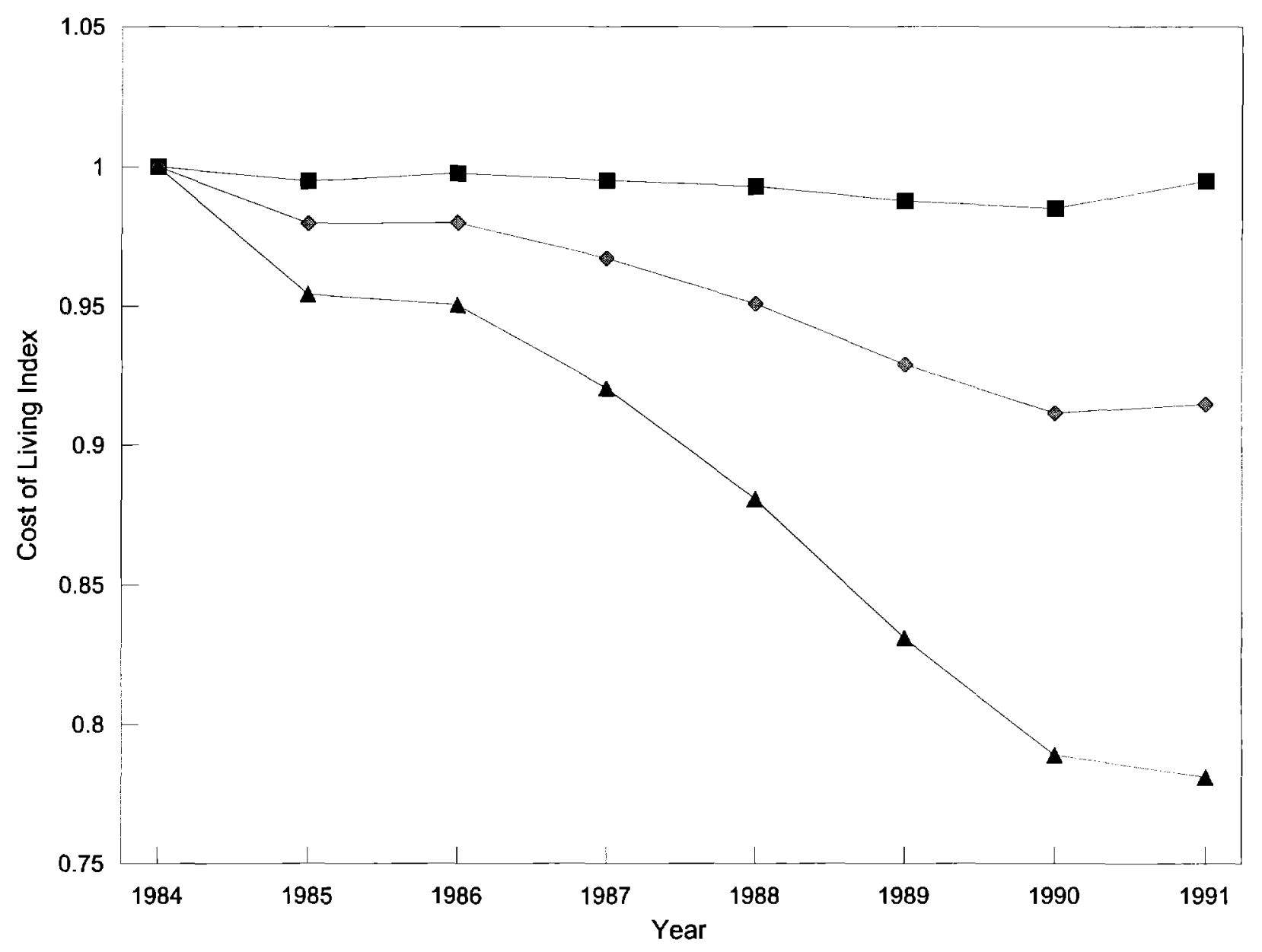

- $\$ 10,000 /$ year $\$ 25,000 /$ year ^ $\$ 50,000 /$ year 
Table 1: Summary of Price Indices

\begin{tabular}{lc}
\hline Index & Real Annual Change \\
\hline Service Price Indices & \\
& \\
Basic Components Price Indices & $3.4 \%$ \\
Medical Care CPI & 6.2 \\
- Hospital component & 6.0 \\
$\quad$ - Room & 5.7 \\
- Other Inpatient Services & 3.3 \\
Synthetic CPI for MTH - Charges & 2.4 \\
Synthetic CPI for MTH - Costs & 2.8 \\
Patient Weighted Price Index - Laspeyres & 2.1 \\
Patient Weighted Price Index - 5-Year Chain Index & 0.7 \\
Patient Weighted Price Index - Annual Chain Index & \\
Treatment Price Indices & \\
Medicare Sample & $0.0 \%,-3.1 \%]$ \\
MTH Sample & $0.6 \%$ \\
Cost of Living Index & 0.4 \\
\hline
\end{tabular}

Note: Service Price Indices are for the 1983-94 period, with the exception of Other Inpatient Services, which begins in 1986. Treatment Price Index for Medicare data and Cost of Living Index are for 1984-91. The values in [.]s for the Cost of Living Index are upper and lower bounds based on alternative estimates of the net value of a lifeyear. 


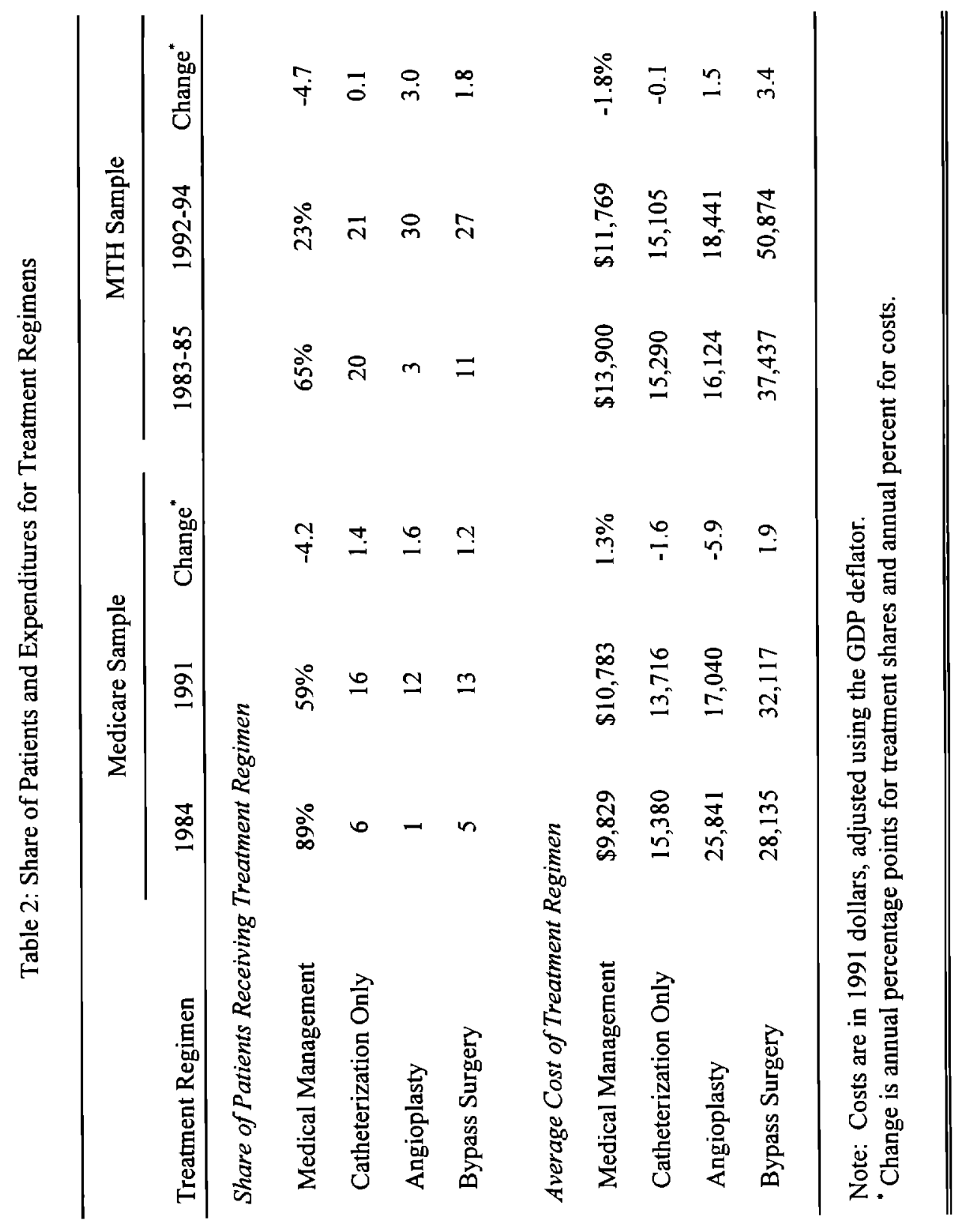




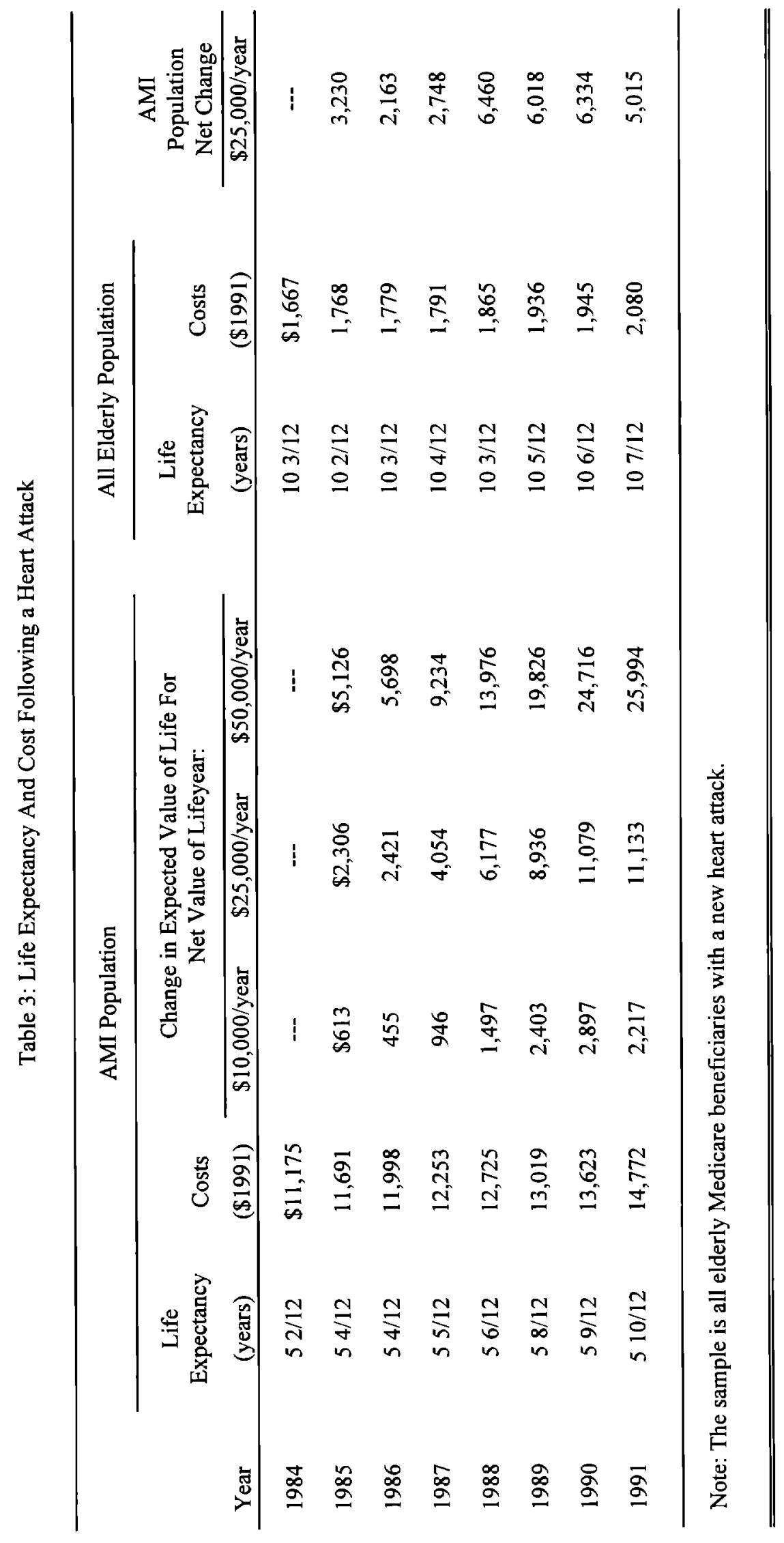


Table A1: Number of Observations

\begin{tabular}{lcc}
\hline Year & $\begin{array}{c}\text { Major Teaching } \\
\text { Hospital }\end{array}$ & Medicare \\
\hline 1983 & 156 & -- \\
1984 & 209 & 233,295 \\
1985 & 205 & 233,898 \\
1985 & 222 & 223,589 \\
1987 & 242 & 227,925 \\
1988 & 214 & 223,199 \\
1989 & 206 & 218,269 \\
1990 & 309 & 221,167 \\
1991 & 365 & 227,182 \\
1992 & 471 & --- \\
1993 & 566 & --- \\
1994 & 477 & --- \\
\hline Note: The numbers are the number of new heart attack episodes & & \\
\hline \hline
\end{tabular}




\section{Appendix 1: Forming Input Price Indices}

\section{The Medical Care CPI}

The hospital component of the medical care CPI is the aggregate of sub-indices for three particular entry-level items: hospital rooms, other inpatient services, and outpatient services. ${ }^{25}$ The CPI is formed in two parts: sampling specific services, and aggregating those services into an index.

Sampling. BLS periodically conducts surveys of consumer spending for hospital services. Hospitals are sampled for the CPI with a probability based on the hospital's share of revenues and are in the index for five years. Replacement of hospitals in the sample is on a staggered basis.

Once a hospital has been selected for the CPI, BLS then finds particular items to be priced. The priced items are in all three entry-level items. Two rooms are automatically selected: a regular room, and an ICU room. To find which other inpatient services are priced, the BLS groups inpatient services into ten clusters (for example, neurology and cardiology are one cluster). Each hospital calculates the share of revenue associated with each cluster, and three clusters are randomly selected, with selection probabilities equal to the revenue share of the cluster in that hospital. Within a sampled cluster, the specific good to be priced (for example, electroencephalogram (EEG) or stress test in the neurology and cardiology cluster) is chosen randomly, again with sampling probability equal to the share of that good in cluster revenue. Finally, within the specific good (for example EEG), the modal type of service is priced.

BLS tries to price the same good every period. If it no longer exists, they ask the hospital for the closest substitute.

Aggregation. BLS uses the specific price quotes to form price indices for the three entry-level items. Denote $i$ as the specific good being priced in stratum $z, h$ as the area of the country, $a$ as the base period (the period when the expenditure survey was taken), and $t$ as the year for which the index is being formed. Thus, phit is the price of good $i$ in area $h$ at time $t$. The relative price increase for each areaitem is:

$$
R_{h z, t i}=\frac{\sum_{i \in z} w_{h i}\left(p_{h i t} / p_{h i a}\right)}{\sum_{i \in z} w_{h i}\left(p_{h i t \prime} / p_{h i a}\right)}
$$

where the weights are the probability that each particular item in each particular hospital was sampled.

Once the relative price increase has been formed, it is straightforward to form the price index for the entry-level item. The index is formed as:

$$
I_{h z, 0}=I_{h z t, 0} R_{h z z, t 1}
$$

25For more detail on the medical care CPI, see Bureau of Labor Statistics (1992). 
The final step is to aggregate the three entry-level indices into the overall hospital CPI. To do this, weights are formed from regional population and spending patterns, based on the Consumer Expenditure Survey. The weight is denoted $A_{h t}$. The CPI is:

$$
I_{\text {hosp US i,o }}=\sum_{h \in U S} \sum_{z \in \text { hosp }} A_{h z} I_{h z, 0}
$$

\section{Synthetic CPI for MTH}

Because our MTH data are for a single hospital and a single disease, our indices are not directly comparable to the official CPI. To try to isolate the effect of methodology from the effect of the particular hospital or disease, we constructed a "synthetic CPI" from our data. We sampled specific goods and weighted them into an index as does the BLS. Since we are pricing a specific disease, the weights we use reflect the share of revenue for that disease resulting from the specific item.

\section{Patient Weighted Price Index}

The Patient Weighted Price Index is formed by repricing the same patient over time. The most difficult issue results from some goods disappearing and others appearing over the course of the sample. If we look at exactly the same price codes, we find that between 27 and 98 percent of goods match over time, depending on the frequency of rebasing (Table A2). Several substitutions between price codes are easily made. For example, in 1988, an intermediate care unit was renamed an intermediate care room. If we make the substitutions that are apparent from these coding changes, we find that we can match between 78 and 98 percent of charges over time.

Table A2: Share of Goods Matched Over Time

\begin{tabular}{lcc}
\hline Frequency of Rebasing & Same Codes & Similar Codes \\
\hline None & $27 \%$ & $78 \%$ \\
Every 5 Years & $42 \%$ & $85 \%$ \\
Every Year & $98 \%$ & $98 \%$ \\
\hline Note: Entries are the dollar-weighted share of goods that can be \\
matched over time. In the case of annual match, the entry is the \\
average percent over the 11 one-year changes. \\
\hline \hline
\end{tabular}

We use the set of goods with similar substitutes over time and omit the remainder of the goods. We have checked whether this differential sampling affects our index, and found it does not.

The goods that cannot be matched after allowing for the substitution of similar codes are generally goods that are prescribed less frequently. By area of hospital, these goods are: 
Table A3: Share of Goods that Cannot be Matched Over 5 Year Interval

\begin{tabular}{lc} 
Part of Hospital & Percent \\
\hline Total & $15 \%$ \\
ICU & 0 \\
OR & 3 \\
Room & 0 \\
Blood & 0 \\
Emergency & 0 \\
Intubation & 0 \\
Invasive Procedures & 3 \\
Laboratory & 3 \\
Oxygen & 0 \\
Pharmacy & 3 \\
Supplies and Devices & 1 \\
Tests & 2 \\
Other & 1 \\
\hline
\end{tabular}

Note: The share that match over time is weighted by dollars. 


\section{Appendix 2: Estimating Changes in Life Expectancy and Cost}

Our calculations on the Cost of Living following a heart attack are divided into two parts.

\section{Valuing life expectancy for AMI patients.}

We divide the AMI population into ten demographic groups, based on age $(65-69 ; 70-74 ; 75-79$; $80-84 ; 85+$ ) and sex. For each cell, we find the number of AMIs each year, and average mortality during the initial hospital admission, at 90 -days post heart attack, and 1-5 years post-heart attack. We also find average Medicare reimbursement in the year after the initial AMI admission. Reimbursement is for any hospital admission, whether related to the heart attack or not. We weight the mortality and reimbursement data by the average demographic mix of the heart attack population over the 1984-1991 period to form adjusted mortality and cost data. All of our subsequent calculations are based on these adjusted data.

To determine the value of life following a heart attack, we need to find the share of the initial heart attack pool who die in each interval after the heart attack. We begin with survival between the heart attack and 5 years after the heart attack. Because our mortality followup data only extend through 1992, we need to extrapolate these values for several years at the end of the time period. For example, we do not observe the share of deaths between 1 and 2 years after an AMI in 1991, and we must extrapolate this from the data we do have. To perform this extrapolation, we first find the hazard rate for each year and interval -- the number of people who die in an interval as a share of the number alive at the beginning of the interval. We assume that the hazard rate is constant at its last observed value for those years and intervals where we are missing it. For example, the hazard rate between 1 and 2 years after an AMI in 1990 was 10.6 percent. We thus assume the hazard rate in 1991 is also 10.6 percent. Since hazard rates are falling over the period where we can measure them (the 1 to 2 year hazard rate was 12.1 percent in 1984), this is likely to be an overestimate of the true hazard rate, and thus an underestimate of the true change in life expectancy. We use the imputed hazard rates to simulate the share of the AMI population dying in each interval.

For those AMI patients surviving 5 years, we need to predict subsequent life expectancy. We do this by forming a simulated life table for AMI survivors. We start with the actual life table for 1984 estimated by the Social Security Administration. Using the age and sex distribution of the heart attack population, we compared the hazard rate for the AMI population between 4 and 5 years in the future ( 10.5 percent in 1984) with the hazard rate for the overall population ( 8.6 percent in 1984). The hazard rate for the AMI population was 21 percent above that for the overall population. We assumed this 21 percent differential persisted every year in the future and formed an AMI life table based on the higher hazard rate. The AMI lifetable, in turn, yields a value for life expectancy conditional on surviving 5 years (6.9 years in 1984). We use this value for 5-year conditional survival in every year between 1984 and 1991 since we have no definitive data on how long-term survival for AMI patients is changing beyond 5 years. This is again likely to understate mortality improvements over time, since survival conditional on living 5 years was improving for the general population over this period, as was AMI survival in the first 5 years after the heart attack.

We assume that someone who died in an interval died halfway through that interval. For example, someone dying between 1 and 2 years after a heart attack would be assumed to have died at 1 
$1 / 2$ years. The average moment alive was $1 / 4$ of the way through the year. The discounted value of life, assuming a 3 percent real discount rate, is therefore $\mathrm{V}=\mathrm{P}\left[1 /\left(1.03^{0.5}\right)+.5 /\left(1.03^{1.25}\right)\right]$.

2. Valuing life expectancy for the general population.

To measure life expectancy and costs for the population as a whole, we use unpublished life tables provided by the Social Security Administration and unpublished data on average Medicare Part A spending from the Health Care Financing Administration. Part A spending is predominantly inpatient services (about 95 percent), with some skilled nursing services and home health care. The data on Part $A$ spending use somewhat different age breakdowns from our AMI data: 65-66; 67-68; 69-70; 71-72; 73$74 ; 75-79 ; 80-84$; and $85+$. We weight the lifetables and cost by the distribution of heart attack patients over the 8 year period. 